\title{
THE LUCKY ONES
}

\author{
After the plague.
}

\section{BY ANDREW DAVID THALER}

$\mathrm{M}$ y legs creak as I climb the stairs to our meeting room. I lean against the wall to steady myself. I could have taken the lift, saved myself the pain, but I need to heal. I am lucky. I can still walk after the disease ravaged my body, but my legs are weak, my arms emaciated, my face scarred and hollow. I keep my body moving, to help it heal. That's why we are all here: to heal.

I don't know why I still come, though. I don't get much from these meetings. They used to be comforting, but now they're just tedious. The survivors, overcome with grief or anger or disgust, are more likely to descend into fits of rage than to open up to any of us about their experiences. They are fighters, they had to be. You didn't survive, uninfected, by being soft. They internalized everything. Many were so consumed with guilt that they couldn't continue. Survivor suicides are an almost daily occurrence now.

I don't remember any of it. Really. One moment my wife and I are lying in bed, coughing violently with a fever that hasn't broken in days; next I wake up, strapped to a hospital bed, my limbs atrophied, my body ruined. It took days for any of it to make sense. Months before I could come to terms with it. My home was destroyed, burned in one of the many fires that swept the city. I don't know where my wife is or what happened to her.

I sit down, silently. It's a mixed group, the survivors and the cured, to "promote healing". These meetings are supposed to be open and anonymous, but the survivors know who the cured are. They can tell by our broken, rotted bodies. Most of the survivors refuse to share their names. I used to bring a picture of my wife to the meetings, on the off chance that a survivor would recognize her, but they never want to look. It's hard to think of us as people again.

I leave the meeting early and alone. Those of us who were cured enjoy being alone with our thoughts. We have been so long without them.

I stop at the corner store to buy some food for Mrs Richmond. Mrs Richmond was a nurse when the outbreak started. She lost her husband and grandson to the plague. She is

$\rightarrow$ NATURE.COM

Follow Futures:

@ @NatureFutures

f go.nature.com $/ \mathrm{mtoodm}$ a tough, no-nonsense woman, and she never watched scary movies. While her neighbours were gunning down

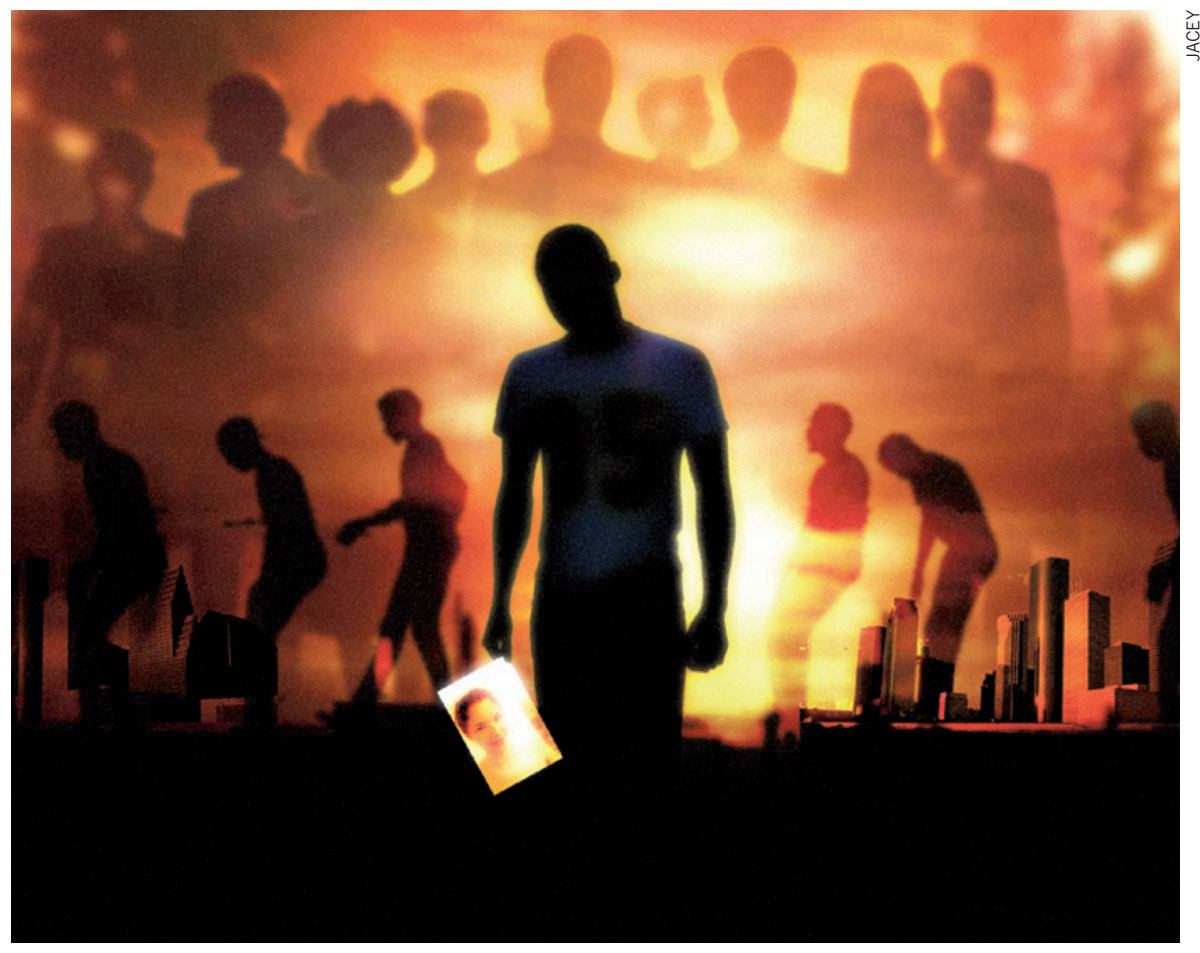

their friends and family, she quietly hid her loved ones in the basement, feeding them when she could. Over the years she saved dozens of infected people, including me, from the rampaging and increasingly desperate mob.

It couldn't have been easy. Once, she tells me, a former neighbour, then head of the local militia, caught wind of her operation. The confrontation ended after a two-day stand-off between Mrs Richmond and four or five militia men. She still won't tell us how it was resolved. She is tough.

I owe her my life. Taking care of her shopping is the least I can do.

Mr Richmond greets me as I turn onto his block. He was once a doctor. He and Mrs Richmond met at the hospital where the outbreak began. He retired decades ago, but still visited her for lunch every day. He was among the first to be infected and his body wasted away during those years, leaving him wheelchair-bound and barely able to speak. But his mind is sharp, and for us, that is all that matters.

I live with the Richmonds now, on a small folding cot in their basement. Even with no memories of it, that basement feels safe.

The TV in the living room is tuned to the news. Another mass suicide of survivors, unable to cope with the consequences of the cure. The bridge, this time.

It's hard to blame them. We, the infected, were insatiable. In our mindless stupor we tore the life from numerous survivors. The illusion was perfect. We had no consciousness. Our bodies rotted where they stood. For all the survivors knew, we were dead, walking corpses slowly decomposing. It must have been terrifying. Those who weren't infected labelled us 'zombies', and, with 50 years of popular culture backing them up, launched an eradication campaign against us. It played out like every movie of the genre: hordes of the 'undead' against a ragtag group of survivors. Overwhelming odds. weren't undead, we were sick.

The survivors call us the lucky ones. We were cured and it was over. We have no memory of the horrible world the disease created. The great mass of humanity became mindless zombies, stalking the living through a dystopian hellscape.

The rest became monsters.

Andrew David Thaler is a postdoctoral researcher studying the ecology and conservation of deep-sea hydrothermal vents. He writes for the popular marinescience blog Southern Fried Science (southernfriedscience.com).
And then someone found a cure. We 